\title{
Anterolateral Thigh Free Flap for Reconstruction of a Severe Degloving Injury: A case report
}

\author{
by Travis Motley, DPM, MS, FACFAS ${ }^{1} \rrbracket$, Kolby White, DPM ${ }^{2} \rrbracket$, Jesse Smith, MD, FACS ${ }^{3}$, \\ Brian Carpenter, DPM, FACFAS ${ }^{4} \rightarrow$, Alan Garrett, DPM, FACFAS ${ }^{5}$
}

The Foot and Ankle Online Journal 3 (1): 3

Degloving injuries with open fractures of the foot and ankle are challenging. We present an injury including soft tissue and bone that required multiple procedures for limb salvage. A multidisciplinary approach was necessary to provide our patient with soft tissue coverage and the best possible outcome.

Key Words: Degloving injury, Free tissue flap, Multidisciplinary approach.

Published: January, 2010

This is an Open Access article distributed under the terms of the Creative Commons Attribution License. It permits unrestricted use, distribution, and reproduction in any medium, provided the original work is properly cited. ๑The Foot and Ankle Online Journal (www.faoj.org)

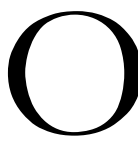
pen fractures with degloving injuries of the foot and ankle present numerous challenges for the patient and the treating surgeons. These injuries often require a multidisciplinary approach for the best possible patient outcome. We describe a 27 year-old Caucasian male who suffered a degloving type injury to his right foot with open calcaneus, talus, navicular, and multiple metatarsal fractures secondary to a motorcycle accident.

Address correspondence to: Travis Motley, DPM, MS, FACFAS, Assistant Professor, University of North Texas Health Science Center, John Peter Smith Hospital, Department of Orthopedics, Podiatry Division, 1500 South Main Street, Ft. Worth, TX 76104. Email: tmotley@jpshealth.org

${ }^{1}$ Assistant Professor, University of North Texas Health Science Center, John Peter Smith Hospital, Department of Orthopedics, Podiatry Division, 1500 South Main Street, Ft. Worth, TX 76104.

${ }^{2}$ PGY-2, John Peter Smith Hospital, Department of Orthopedics, Podiatry Division, 1500 South Main Street, Ft. Worth, TX 76104.

${ }^{3}$ Assistant Clinical Professor, University of Texas Southwestern Medical Center, Facial Plastic and Reconstructive Surgery, John Peter Smith Hospital, Department of Surgery, 1500 South Main Street, Ft. Worth, TX 76104.

${ }^{4}$ Associate Professor, University of North Texas Health Science Center, John Peter Smith Hospital, Department of Orthopedics, Podiatry Division, 1500 South Main Street, Ft. Worth, TX 76104.

${ }^{5}$ Assistant Professor, University of North Texas Health Science Center, John Peter Smith Hospital, Department of Orthopedics, Podiatry Division, 1500 South Main Street, Ft. Worth, TX 76104.

\section{Case Report}

A 27 year-old male presented to the Emergency Department after suffering a motorcycle injury. The patient had no significant past medical or surgical history, took no medications, reported no food or drug allergies, but admitted to smoking 1 pack of cigarettes a day for the past 8 years. His right lower extremity was his only injury. (Fig. 1) The patient was consulted to the trauma service and underwent an urgent irrigation of his wounds to his right foot and ankle without introduction of fixation. Intraoperatively, the posterior tibial artery was found to be transected at the level of the medial malleolus and was ligated during this initial operation with suture. 


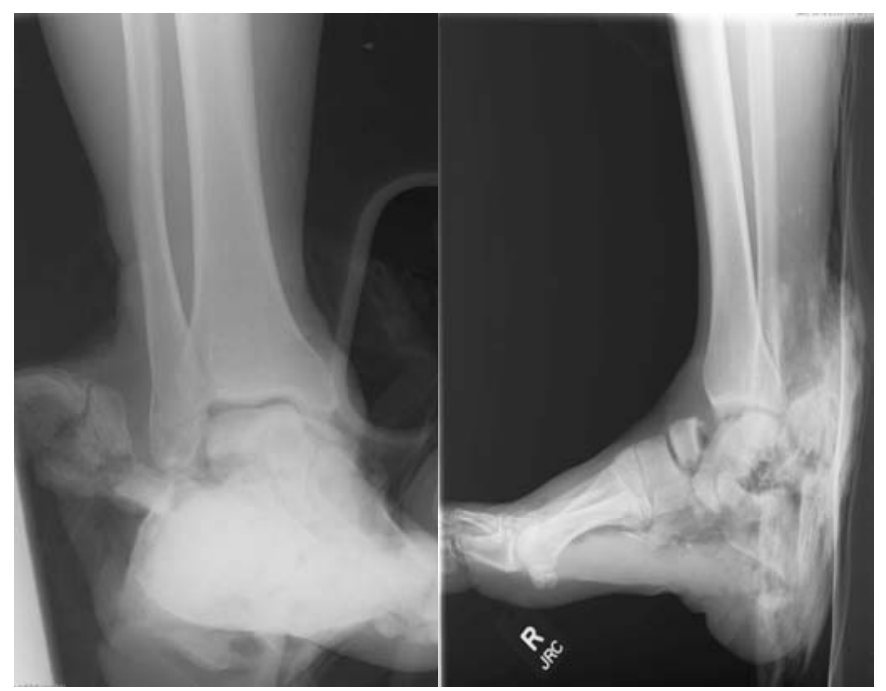

Figure 1 Initial pre-operative radiographs demonstrating calcaneus, talus, and navicular fractures with dislocation of the subtalar and talonavicular joints.

The patient returned to the operating room 3 days later for repeat irrigation with debridement and placement of percutaneous Kirshner wire fixation. (Figs. 2 - 4) A wound VAC (K.C.I., San Antonio, TX) was placed with incisional VAC technique ${ }^{1,2}$ over the soft tissue suture line that extended from the Achilles insertion to the first metatarsal base and a soft tissue defect present in the proximal portion of the wound. The VAC was changed on the ward on day 6 for the defect, and the incisional component was discontinued. The patient returned to the operating room for debridement of skin necrosis on day 10. This debridement produced a substantial medial foot wound, encompassing nearly $35-40 \%$ of the foot surface area, with the majority of the defect medially and posteriorly. (Fig. $5 \mathrm{~A}$ and B) The calcaneus was exposed but showed viable periosteum, normal bleeding potential, and no signs of infection. The periphery of the wound demonstrated small pockets of purulence and was lavaged with three liters of normal saline and the wound VAC was reapplied.

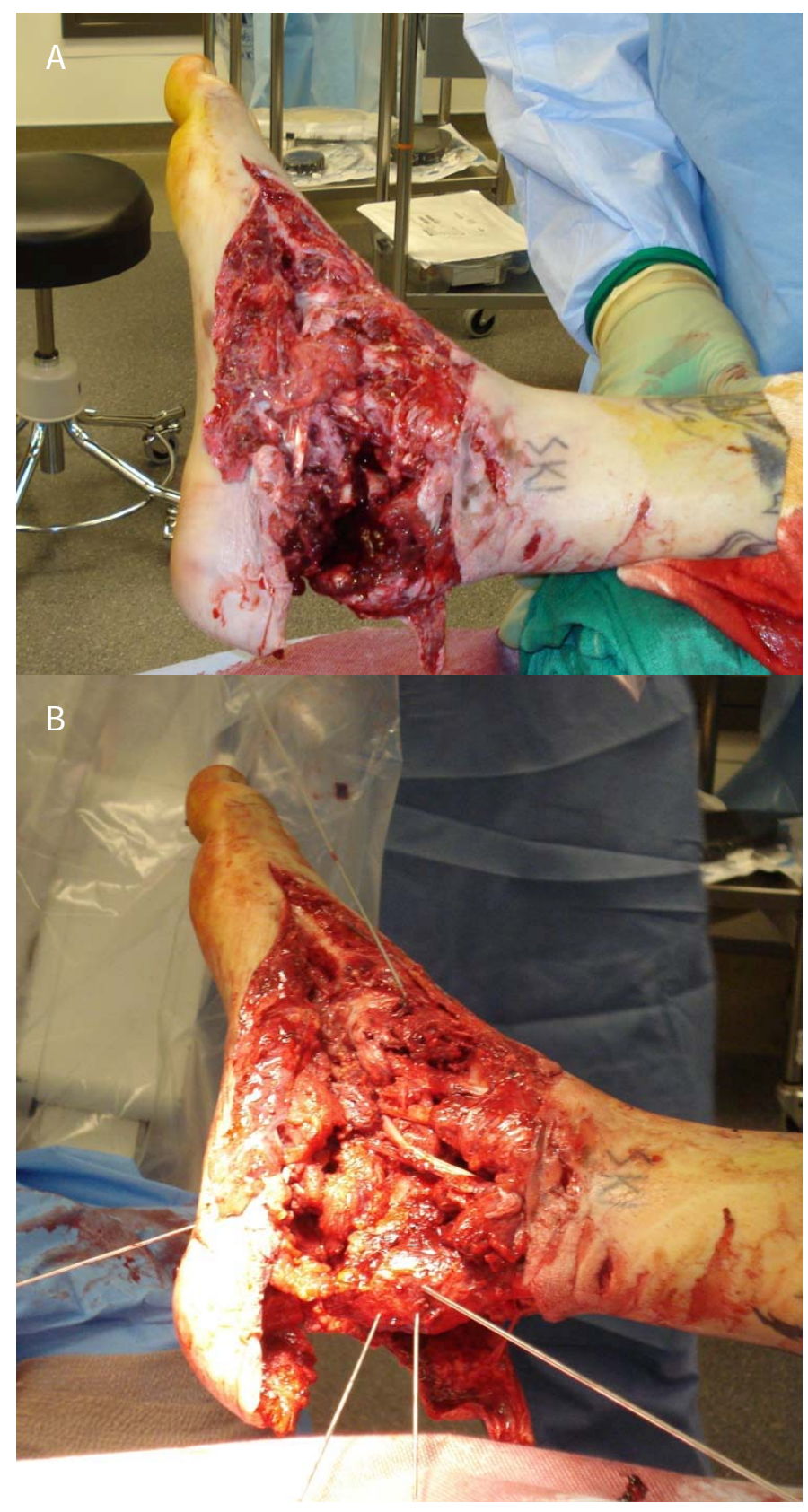

Figure 2 Intra-operative findings at the second irrigation with before $(A)$ and after $(B)$ placement of fixation.

The wound VAC was changed next on day 14 in the OR. The wound showed no clinical signs of infection and was lavaged with three liters of normal saline. Integra Bilayered Wound Matrix Dressing (BWMD) (Integra LifeSciences, Plainsboro, NJ) was applied directly over the exposed bone, tendons, and neurovascular structures with a wound VAC. 


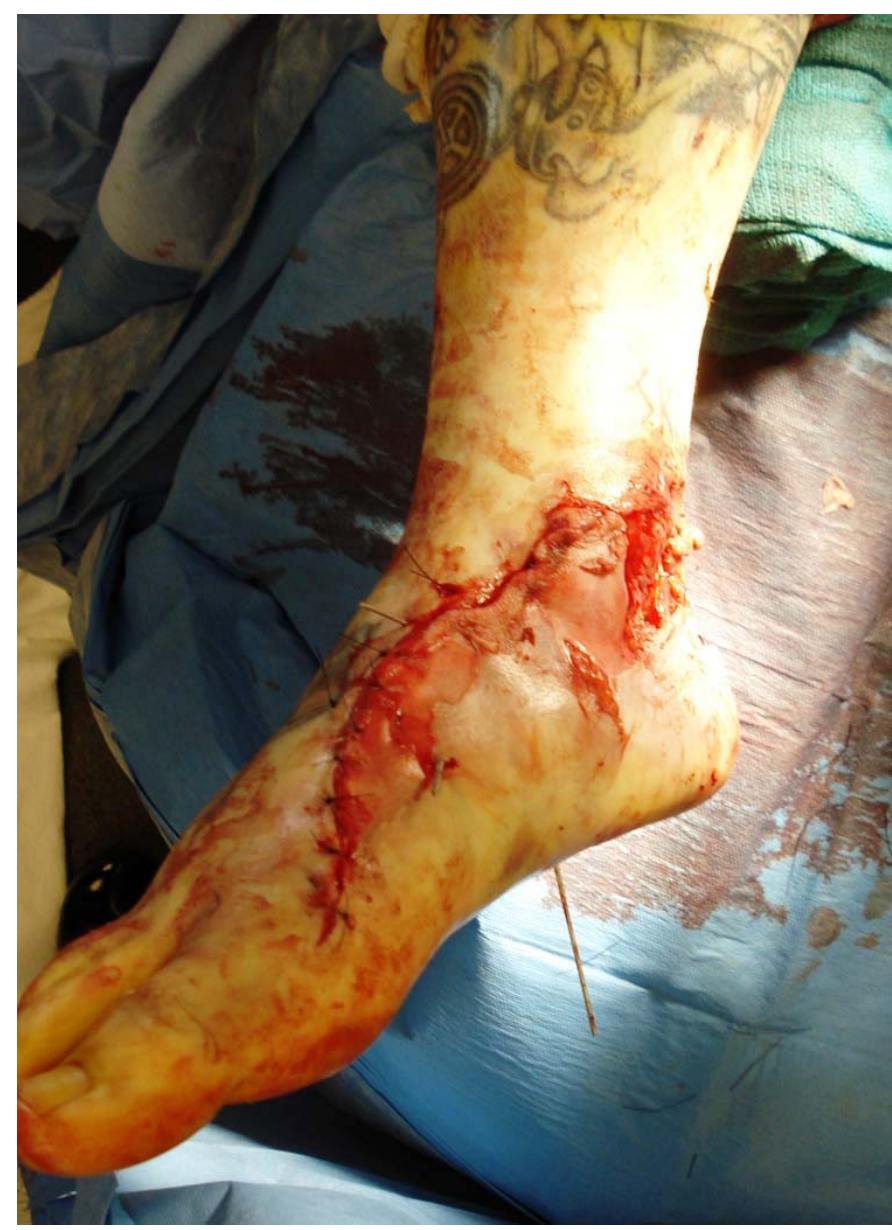

Figure 3 Initial closure of extensive medial and posterior wounds.

The VAC was changed on the ward on day 18. On day 22 there was noted to be a substantial hematoma present underneath the Integra graft and the patient was returned to the operating room for evacuation of the hematoma and replacement of the VAC. On day 27, a repeat irrigation and debridement was performed at the time of the VAC change. On day 30, Integra BWMD was applied again with a wound VAC application. The wound continued to show significant improvement with incorporation of the Integra and a granular wound base. At this time, the patients wound measured $240 \mathrm{~cm}^{2}(10 \mathrm{~cm} \times 24 \mathrm{~cm})$.

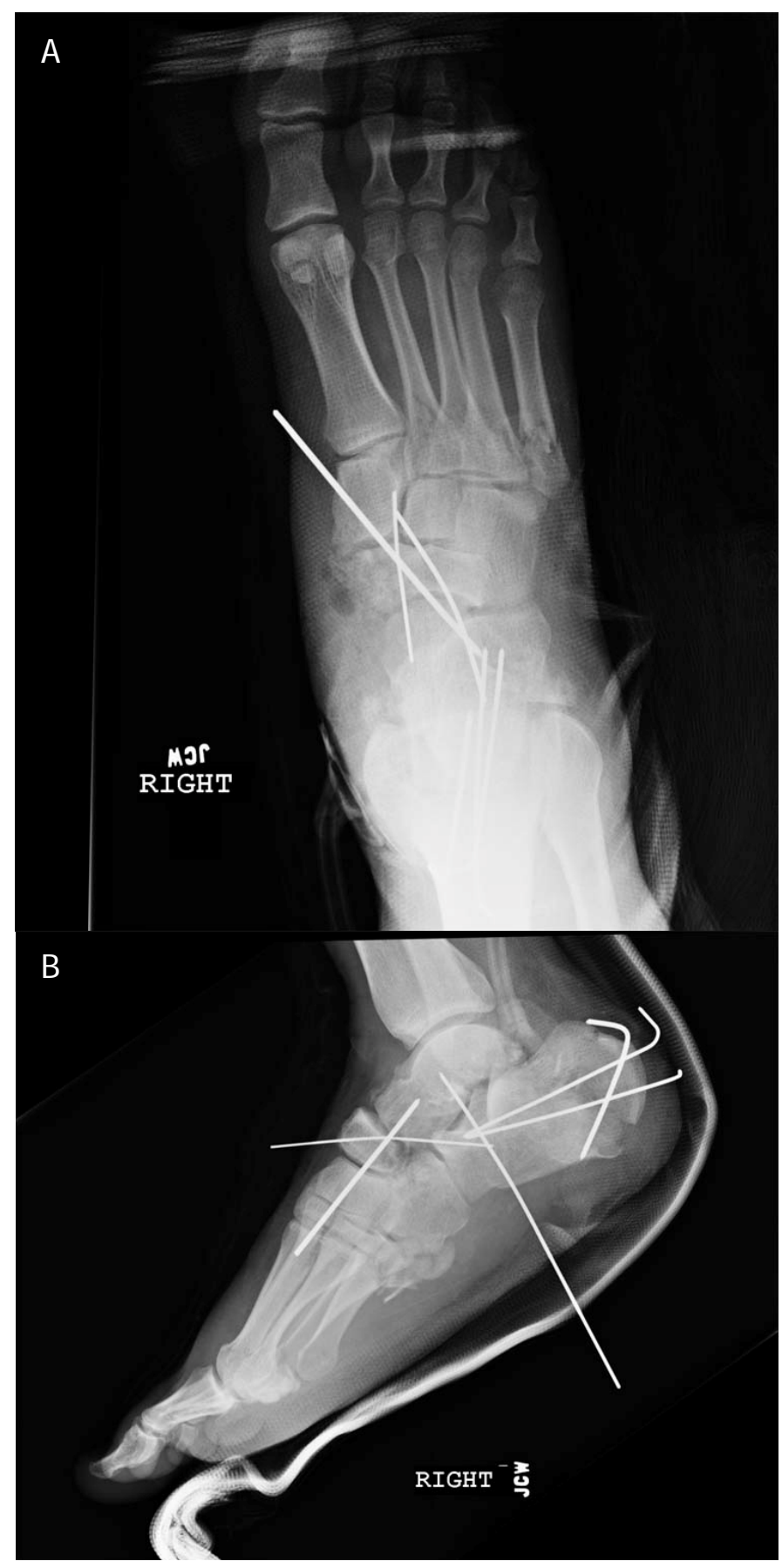

Figure 4 Post-operative radiographs demonstrating gross reduction with fixation ( $A$ and $B$ ). 


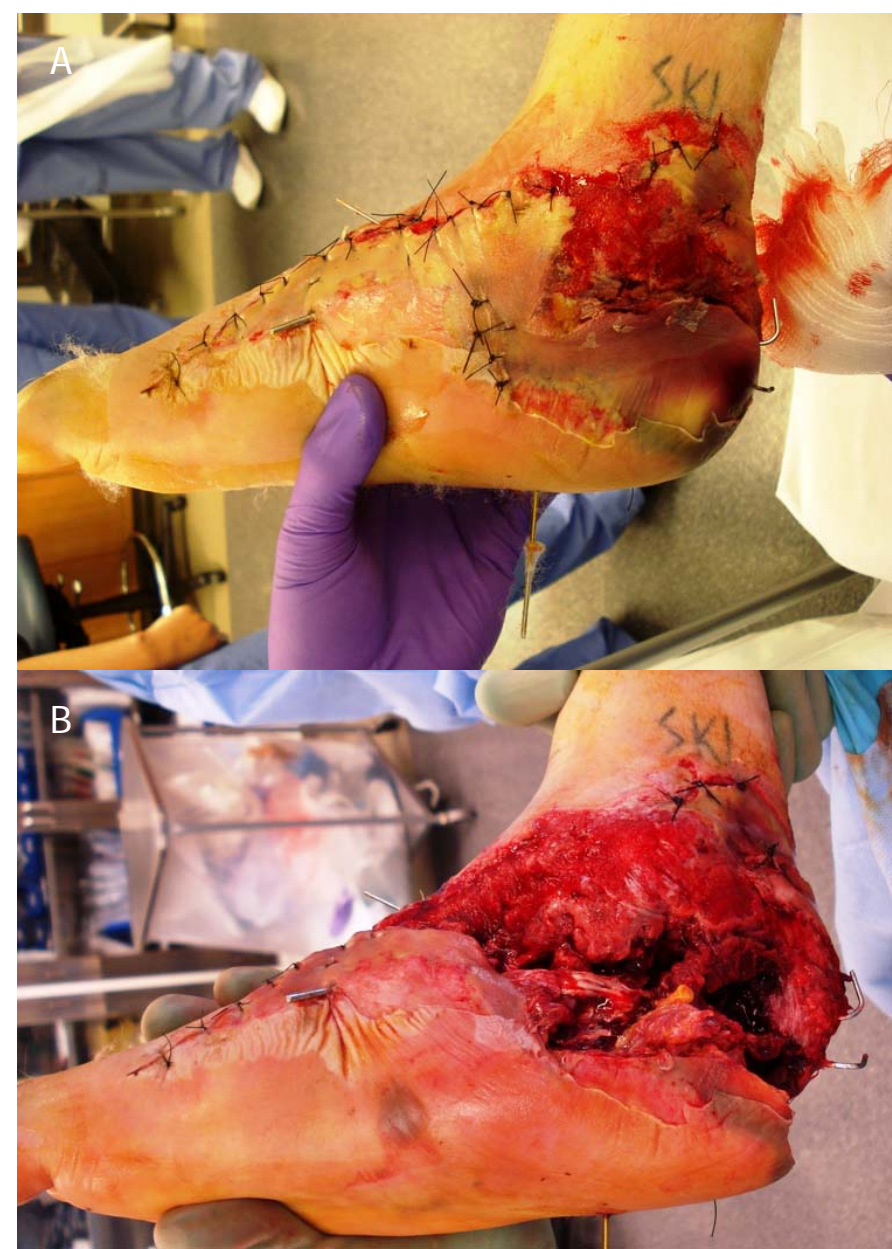

Figure 5 Subsequent devitalization of posterior and medial tissues on day 10 both pre-operatively (A) and post debridement (B).

Throughout the patient's stay, capillary fill time to all toes remained brisk. The large soft tissue loss medially presumably occurred due to the initial soft tissue insult and possibly ligation of the lacerated posterior tibial artery during the initial operation. Although the wound continued to show signs of improvement, the long course of treatment was difficult for the patient both emotionally and financially. At the patient request, a consultation was obtained for a below the knee amputation. After considering this option, the patient decided to continue with limb salvage.

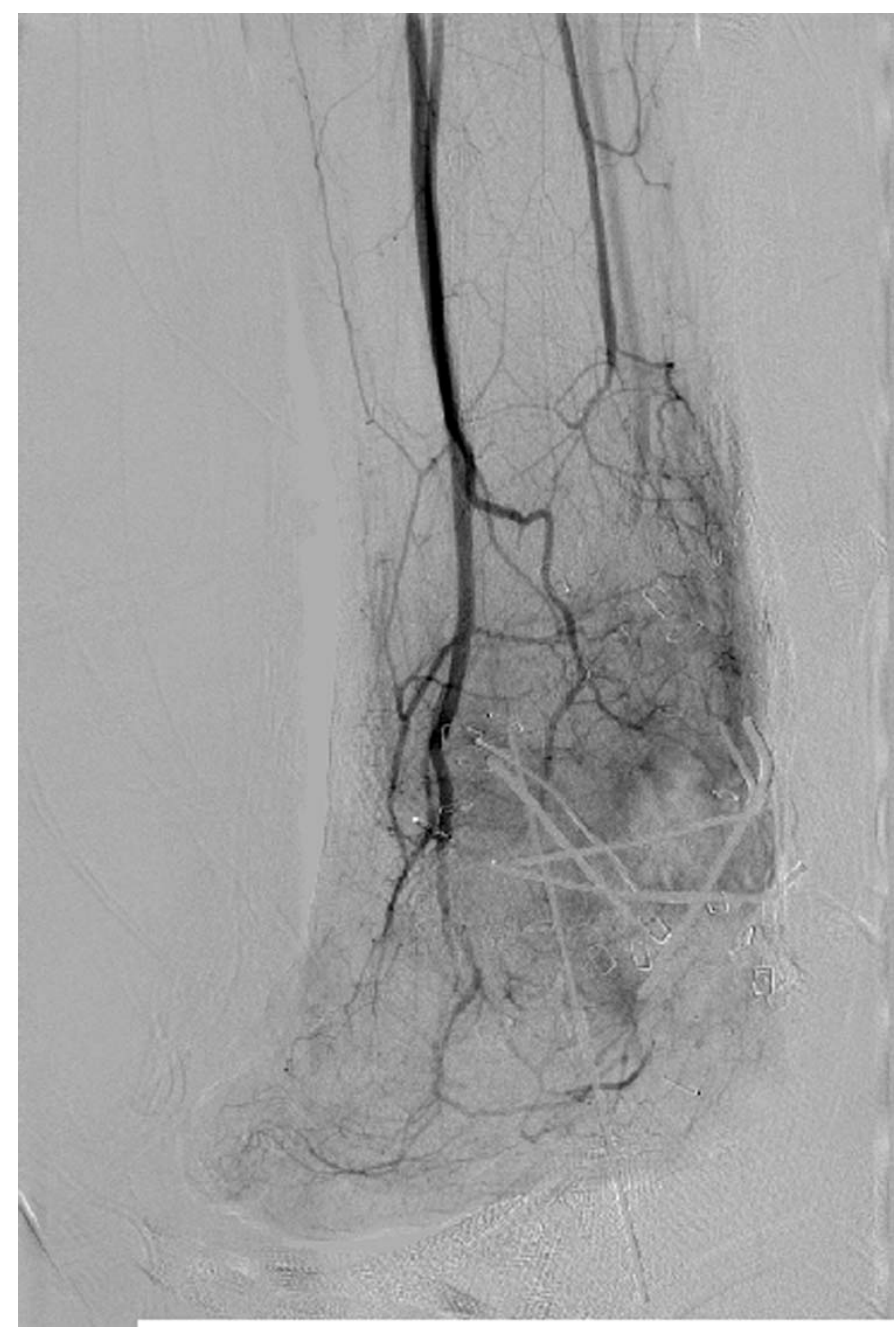

Figure 6 Angiogram demonstrating previously ligated posterior tibial artery at index procedure.

After consultation with the Facial Plastic Surgery Service, an angiogram was performed that demonstrated termination of the posterior tibial artery at the site of previous ligation at the level of the medial malleolus. The dorsalis pedis and peroneal arteries were patent. (Fig. 6)

On day 35, a free tissue flap (anterolateral thigh free flap coupled to the tensor fascia lata) was applied with the reconstructive facial surgeon. (Fig. $7 \mathrm{~A}$ and B) Anastamosis of the flap pedicle was performed to the posterior tibial artery proximal to the level of previous ligation. 


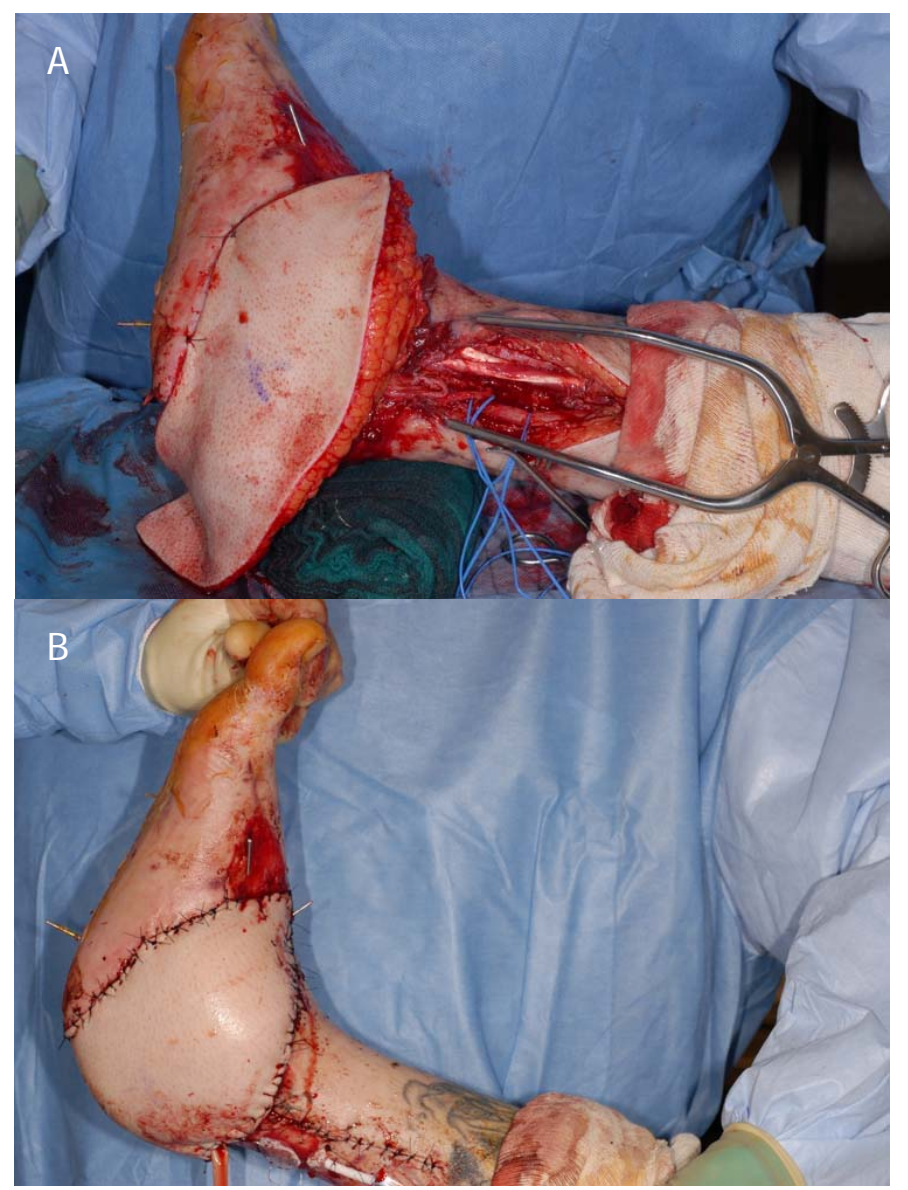

Figures 7 Intraoperative contralateral fascia lata flap harvest (A) with transfer to the soft tissue defect (B).

Two venae communicants were also anastamosed during this tissue transfer. Total flap ischemic time was 125 minutes. After reperfusion, the flap demonstrated a brisk hyperemic response. An implantable Doppler was placed which revealed triphasic blood flow and would be utilized for continued monitoring over the next week. The remaining portion of the flap was closed over a $4 \mathrm{~mm}$ flat Jackson-Pratt drain, which was removed on post operative day five. After flap coverage a $3 \mathrm{~cm}$ x $5 \mathrm{~cm}$ defect still remained to the dorsal aspect of the foot, but was superficial and granular in nature. An offloading non-circumferential dressing was placed, and the patient returned to his room for close overnight monitoring of the free flap.

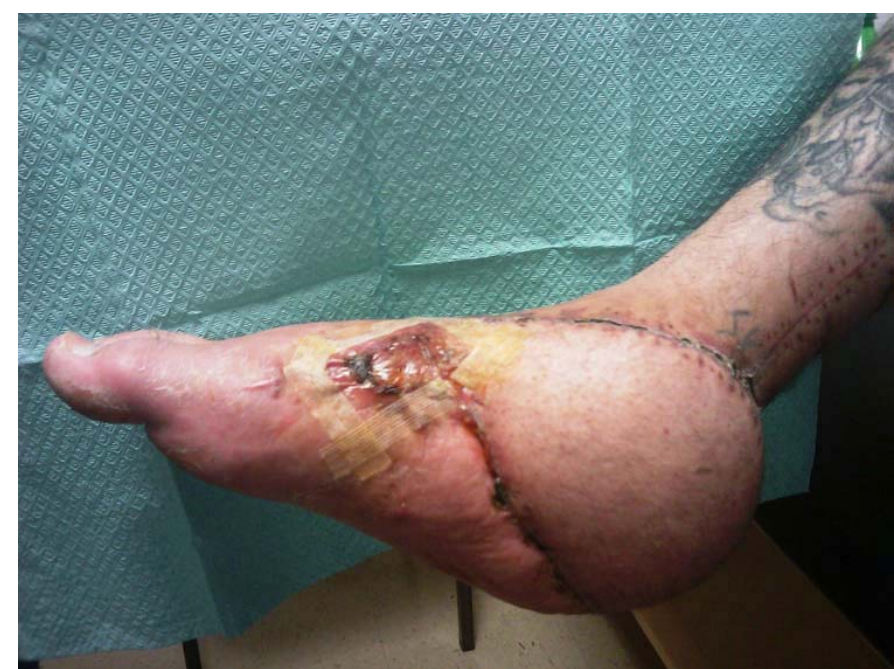

Figure 8 One week status post Apligraf application to the remaining medial foot wound.

The remaining portion of the patient's stay was unremarkable and he continued to progress and improve. The patient was on strict bed rest for the first week. After seven days, the patient was nonweight bearing with crutches and allowed to place his right foot in a dependent position with slowly increasing intervals. A small, $1 \mathrm{~cm}$ wound developed at the plantar aspect of the heel presumably from pressure at this incision line that was covered with a nonadherent dressing. At the 4 week follow-up, the free flap was completely incorporated and sutures were removed. The remaining wound that was not covered with the flap was addressed at this time. Apligraf (Organogenesis, Canton, MA) was placed (Fig. 8) and by 3 weeks all wounds were healed with the exception of a small wound at the plantar heel at an area of flap attachment. Radiographs revealed proper alignment of the talonavicular joint and the calcaneus and navicular fractures appeared to be healing well without clinical signs of infection. Three months after free tissue transfer and supplemental Apligraf application, all soft tissue wounds were resolved. (Fig. $9 \mathrm{~A}$ and B) 


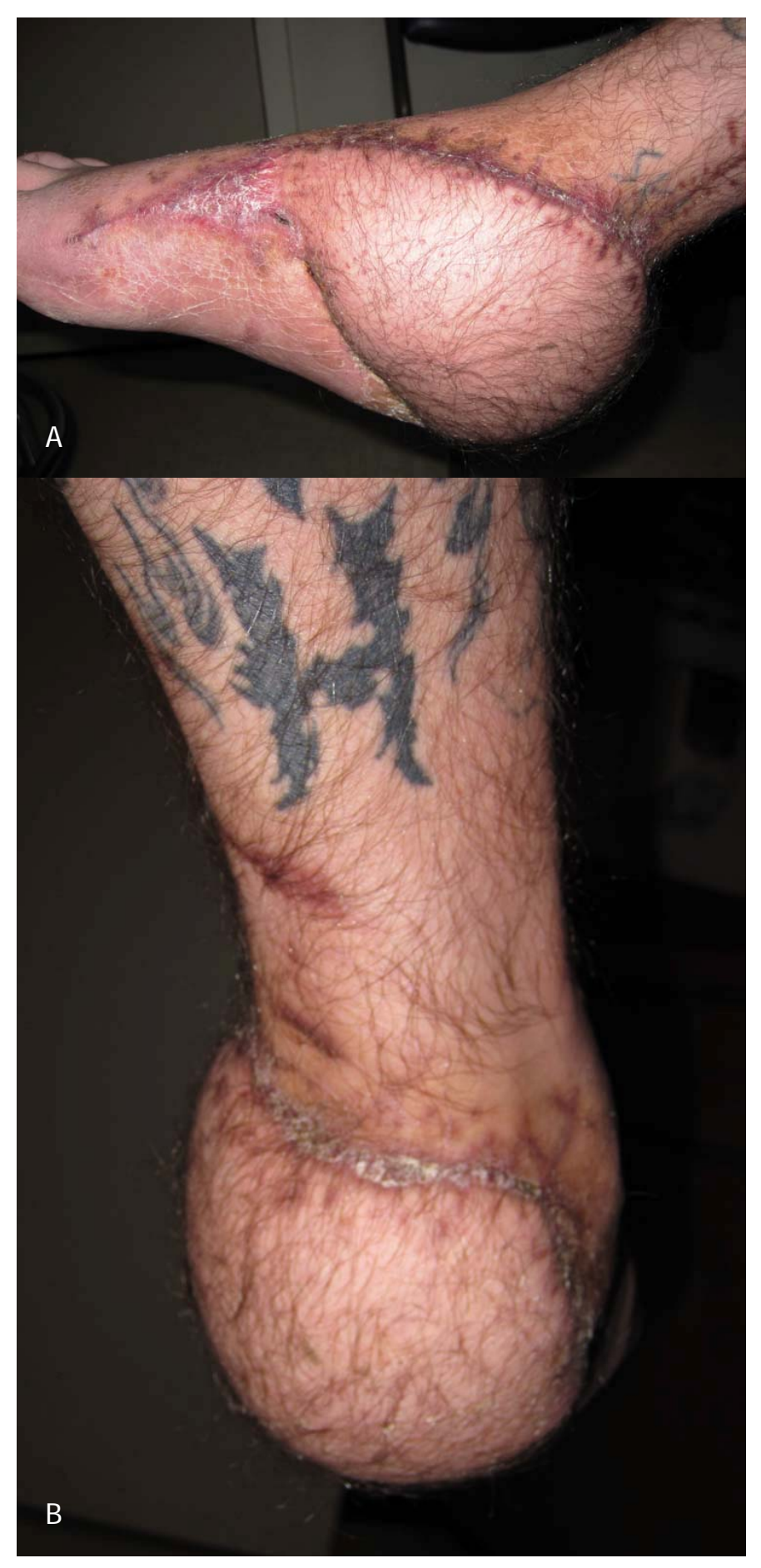

Figure 9 Four weeks after Apligraf application and 3 months after free flap ( $A$ and $B$ ).

\section{Discussion}

Severe degloving injuries present a challenge to surgeons which require a multi-disciplinary approach. Previous studies have demonstrated techniques for soft tissue coverage of plantar foot ${ }^{3}$ and heel ${ }^{4}$ wounds. We present the alternative pathway of incorporating a surgeon with a background in complex tissue transfer. Incorporating a reconstructive facial surgeon in the management of our patient when a plastic surgeon was not otherwise available was vital to the success of this particular limb salvage. Initial stabilization was performed by the foot and ankle service with fixation of the fractures to help stabilize the soft tissues followed by repeated debridements. Once the patient had committed to continue with limb salvage, the anterolateral thigh free flap was chosen by the reconstructive facial surgeon for its versatility and its relative low morbidity.

Briefly, the anterolateral thigh flap is a relatively new free tissue transfer and has been described for soft tissue coverage in other than the foot and ankle. ${ }^{5}$ It is a versatile flap that allows for minimal donor site morbidity and preserves major muscle function. The flap allows for a large amount of tissue, thus coverage of a large defect. The size of the flap is limited to the patient's body habitus, but can encompass $8 \times 25 \mathrm{~cm}$. Generally, the donor site can be primarily closed or grafted with a split thickness skin graft if the area is too broad. The anterolateral thigh flap lies on the axis of the septum dividing the vastus lateralis and the rectus femoris muscles. Arterial inflow is supplied by the descending branch of the lateral femoral circumflex artery. This branch arises from the profunda femoral trunk. ${ }^{6,7}$ In this patient the facial plastic surgery team also included the perforators to the iliotibial band. By including this arterial supply, a wider dimension could be obtained from the anterolateral thigh free flap which included the vascularized ventral half of the tensor fascia lata. This was needed to cover the large $10 \times 24 \mathrm{~cm}$ ankle and foot defect. 
Debate exists on the necessity for cutaneous innervation of the flap but regardless, has proven to provide durable coverage for the weight-bearing surface. Without a team approach, the patient would have likely undergone an amputation and suffered future physical, financial, and psychological consequences. As a result of the multiple disciplines involved, we were able to obtain a good result in this particular limb salvage.

\section{References}

1. Herscovici D Jr, Sanders RW, Schauta JM, Infante A, DiPasquale T: Vacuum-assisted wound closure (VAC therapy) for the management of patients with high-energy soft tissue injuries. J Orthop Trauma 17(10): 683 - 688, 2003.

2. Banwell PE, Musgrave M: Topical negative pressure therapy: mechanisms and indications. Int Wound J 1(2): 95 - 106, 2004. 3. Zgonis T, Cormack DT, Stapleton JJ: Utilizing a crossover reverse sural artery flap for soft tissue reconstruction of the plantar forefoot after a severe degloving injury. Int J Low Extrem Wounds 6 (2): 114 - 119, 2007.

4. Basile A, Stopponi M, Loreti A, Minniti de Simeonibus AU: Heel coverage using a distally based sural artery fasciocutaneous cross-leg flap: report of a small series. J Foot Ankle Surg 47(2): $112-117,2008$

5. Muneuchi G, Suzuki S, Ito O, Saso Y: One-stage reconstruction of both the biceps brachii and triceps brachii tendons using a free anterolateral thigh flap with a fascial flap. J Reconst Microsurg 20: 139 - 142, 2004.

6. Koshima I, Yamamoto H, Hosoda M, Moriguchi T, Orita Y, Nagayama H: Free combined composite flaps using the lateral circumflex femoral system for repair of massive defects of the head and neck regions: an introduction to the chimeric flap principle. Plast Reconstr Surg 92: 411 - 420, 1993.

7. Lou S, Raffoul W, Luo J, Luo L, Gao J, Chen L, Egloff DV: Anterolateral thigh flap: a review of 168 cases. Microsurgery 19: 232 - 238, 1999.

8. Ducic I, Hung V, Dellon A: Innervated free flaps for reconstruction: a review. J Reconstr Microsurg 22(6): 433 - 442, 2006. 